\title{
EVALUASI MATERIAL RADIANT TUBE HEATER DI UNIT REFINERY MENGGUNAKAN METODE TEKNIK REPLIKA DAN KEKERASAN
}

\section{EVALUATION OF THE HEATER RADIANT TUBE MATERIAL IN THE REFINERY UNIT USING REPLICA TECHNIQUE AND HARDNESS TEST METHOD}

\author{
M. Syahril, Kurniasih \\ Balai Besar Teknologi Kekuatan Struktur - BPPT, Kaw. PUSPIPTEK, Gdg. 220.
}

\begin{abstract}
Abstrak
Makalah ini membahas evaluasi material radiant tube heater di unit refinery yang telah beroperasi selama \pm 15 tahun menggunakan metode teknik replika dan uji kekerasan. Secara visual, material tabung yang merupakan spesifikasi $1 \frac{1}{4} \mathrm{Cr}-1 / 2 \mathrm{Mo}-\mathrm{Si}$ telah terdegradasi karena paparan suhu tinggi untuk layanan yang lama. Evaluasi dilakukan secara analitik untuk mengetahui kondisi aktual material dan memastikan keandalan tabung pada beban pengoperasian di masa depan. Penelitian ini dilakukan dengan inspeksi visual, struktur mikro dengan teknik replika dan pengujian kekerasan material dengan instrumen pengujian kekerasan portabel. Secara umum, hasil pengamatan menunjukkan bahwa struktur mikro dari material tabung radiasi mengandung ferit dan fase perlit spheroidisasi, batas butir masih terlihat jelas. Nilai kekerasan minimum dari material radiant tube heater adalah $127 \mathrm{HB}$ (Hardness Brinell) yang identik dengan $438 \mathrm{MPa}$ dari nilai kekuatan tarik. Secara analitik, kekuatan bahan tabung radiasi masih dalam kriteria spesifikasi standar material $1 \mathrm{Cr}-1 / 2 \mathrm{Mo}-\mathrm{Si}$, di mana kekuatan standar minimum adalah $415 \mathrm{MPa}$. Berdasarkan analisis struktur mikro dan nilai kekerasan, dapat disimpulkan bahwa material tube heater masih layak dan dapat diandalkan untuk berfungsi sesuai dengan kriteria desain untuk operasi.
\end{abstract}

Kata Kunci : Material, Tube heater, Struktur mikro, Kekerasan, Handal

\begin{abstract}
This paper discusses the evaluation of the heater radiant tube materials in the refinery unit that has been operating for \pm 15 years using replica technique methods and hardness tests. Visually, the tube material which is a specification of $11 / 4 \mathrm{Cr}-1 / 2 \mathrm{Mo}-\mathrm{Si}$ has degraded due to high temperatures exposure for long service. The evaluation was done analytically to find out the actual condition of the material and ensure the reliability of the tube at the future operating loads. This research was conducted by visual inspection, microstructure with replica techniques and material hardness testing with portable hardness testing instruments. Generally, the observation results show that the microstructure of the material of the radiant tube contains ferrite and spheroidization pearlite phase are still in good condition, the grain boundaries are still clearly visible. The minimum hardness value of the radiant tube material is $127 \mathrm{HB}$ (Hardness Brinell) which is identical to $438 \mathrm{MPa}$ of the tensile strength value. Analytically, the radiant tube materials strength is still in the standard material specification criteria of $1 \mathrm{Cr}-1 / 2 \mathrm{Mo}-\mathrm{Si}$, where the minimum standard strength is $415 \mathrm{MPa}$. Based on the microstructures and hardness values analysis, that can be concluded that the heating tube material is still feasible and that it can be reliable to function in accordance with the design criteria for operation.
\end{abstract}

Keywords; Material, Tube heater, Microstructure, Hardness, Reliable.

Diterima (received ) : 18 Juli 2019 , Direvisi (revised ) : 08 Oktober 2019 ,

Disetujui (accepted) : 22 Oktober 2019 


\section{PENDAHULUAN}

Proses fire-heater adalah proses pemanasan tungku oleh gas yang dihasilkan oleh pembakaran bahan bakar cair atau gas, dimana di dalam tungku terdapat tube-tube yang mengalirkan cairan yang dipanas. Pemanas semacam ini banyak digunakan dalam kilang minyak dan pabrik petrokimia untuk keperluan pemanasan yang terdiri dari dua tipe dasar konfigurasi struktur yaitu: Silinder, kotak, kabin dan kotak multi-sel dan konfigurasi tube meliputi vertikal, horizontal dan spiral. Pemanasan tube terdiri dari dua bagian yaitu radiant tube area dan convection tube area. Seikitar $45-55 \%$ dari total gas panas dalam tungku ditransfer ke cairan di dalam radiant tube, $25-45 \%$ gas panas ditransfer ke cairan dalam convection tube dan terbuang melalui cerobong (stack). ${ }^{1,2,3)}$

Heater yang digunakan dalam proses pengolahan minyak mentah sebagai media perpindahan panas sebelum dilakukan proses destilasi atau pemisahan untuk mendapatkan berbagai varian produk minyak seperti naphta, bensin, solar dan lainnya yang terkandung di dalam minyak tersebut. Heater yang merupakan satu kesatuan terdiri dari tube, burner dan ruang bakar.3,4,5)

Komponen yang beroperasi pada suhu tinggi dan bertekanan atau mempunyai tegangan statis maupun dinamis dalam jangka waktu yang lama serta dimungkinkan adanya faktor lingkungan yang korosif dapat menyebabkan kerusakan pada komponen tersebut sehingga faktor ini akan menimbulkan kerugian secara finansial yang sangat besar, maka dalam masa tertentu evaluasi terhadap kondisi material tube harus dilakukan seoptimal mungkin dan berdasarkan pedoman atau kriteria pemeliharaan dan pengoperasian yang telah dibuat atau desain.

Adapun jenis-jenis kerusakan material tube heater tersebut adalah kerusakan akibat creep, fatik, over heating, penipisan ketebalan akibat korosi, korosi retak tegang, korosi erosi, korosi kavitasi, oksidasi, dekarburisasi, karburisasi, spherodisasi, dan lain-lain.6,7)

Oleh karenanya, material tube heater harus dalam kondisi yang aman dan handal saat dioperasikan untuk menghindari dan/atau meminimalkan kerugian yang ditimbukan akibat kerusakan yang tidak dapat terdeteksi sebelumnya, maka dalam rangka pemeliharaan (maintanances) refinery heater yang telah beroperasi selama \pm 15 tahun, Dimana kondisi temperatur operasi permukaan luar (skin temperatur) dari tube adalah material radiant tube heater saat dioperasikan sebesar $380-440 \quad{ }^{\circ} \mathrm{C}$ dan didesain hingga $520^{\circ} \mathrm{C}$, tekanan operasi 330 $360 \mathrm{psi}$, diameter 4,5 inch dengan ketebalan 7,3 $\mathrm{mm}$.

Material radiant tube heater merupakan fokus dari studi ini untuk mengevaluasi kondisi aktualnya sehingga tingkat kerusakannya dapat diketahui secara dini dan program perencanaan penggantian material radiant tube heater (replacement of tube) dengan ukuran dan spesifikasi teknis tertentu dapat dilakukan dengan terencana dan mudah serta ekonomis.

\section{BAHAN DAN METODE PERCOBAAN}

Material/bahan penelitian terfokus pada material tube refinery heater yang merupakan spesifikasi dari JIS (Japan Industrial Standard) STPA 234) yang mengandung unsur kimia $1 \frac{1}{4} \mathrm{Cr}-1 / 2 \mathrm{Mo}^{8}$

Tabel 1.

Komposisi kimia material radiant tube refinery heater

\begin{tabular}{lll}
\hline Unsur & Simbol & Berat (\%) \\
\hline Carbon & $\mathrm{C}$ & $0,15 \mathrm{max}$ \\
Silicon & $\mathrm{Si}$ & $0,50-1,00$ \\
Manganase & $\mathrm{Mn}$ & $0,30-0,60$ \\
Chromium & $\mathrm{Cr}$ & $1,00-1,50$ \\
Molybdenum & $\mathrm{Mo}$ & $0,45-0,65$ \\
Sulphur & $\mathrm{S}$ & $0,30 \mathrm{max}$ \\
Phospor & $\mathrm{P}$ & $0,30 \mathrm{max}$ \\
\hline
\end{tabular}

\section{Metode Percobaan}

Kondisi material tube heater yang telah terpasang dan dioperasikan dalam waktu yang lama pada temperatur tinggi merupakan fokus dari penelitian ini. Percobaan dilakukan di lokasi proses pada saat produksi dihentikan untuk pemeliharaan peralatan secara rutin (turn around) dengan tanpa merusak komponen-komponen lainnya. Adapun prosedur percobaan yang digunakan dalam penelitian ini adalah sebagai berikut :

Pengamatan Visual

Pengamatan visual yang didokumentasikan dengan menggunakan kamera digital bertujuan untuk memverifikasi permasalahan yang terjadi pada tube heater yaitu berupa konsisi aktual tube setelah beroperasi dalam waktu yang lama seperti kemungkinan adanya hot spot, penumpukan 
oksida/ deposit pada permukaan tube dan indikasi lain yang dapat menyebabkan percepatan kerusakannya. Pengamatan visual juga bertujuan untuk menentukan lokasi pemeriksaan struktur mikro dan kekerasan dari material tube heater.

Teknik Replika

Pemeriksaan dengan teknik replika untuk melihat kondisi struktur mikro yang mengacu pada standar ASTM E 1351-019) yang meliputi beberapa tahapan yaitu:

- Proses grinding menggunakan mesin grinding untuk menghilangan kotoran yang berupa lapisan oksida (scale) atau deposit di area permukaan tube yang telah ditentukan lokasinya. Kemudian, preparasi dilanjutkan dengan proses pengampelasan (sanding) menggunakan mesin grinding/ polishing dan kertas ampelas silicon carbide (SiC) dengan variasi kekasaran yaitu dari 60 hingga 1200 mesh. Proses pembersihan/ pencucian permukaan sampel menggunakan alkohol 95\% setelah selesai penghamplasan dan dikeringkan dengan kertas tisue.

- Proses pemolesan (polishing) sampel uji tube menggunakan media diamond pasta yang berukuran $1 / 4$ mikron sehingga permukaan yang dipreparasi menjadi seperti kaca. Selanjutnya, permukaan yang telah memenuhi syarat preparasi dilakukan etsa (etching) menggunakan larutan nital $2 \%$.

- Plastik replika yang bertindak sebagai replektor ditetesi larutan ethanol dan ditempatkan pada permukaan sampel yang telah dipoles dan dietsa, seperti terlihat pada gambar 1 yaitu foto visual hasil preparasi tube untuk pemeriksaan struktur mikro.

- Plastik replika dilepaskan setelah mengering dan ditempatkan pada permukaan yang rata. Selanjutnya, plastik replika tersebut diamati menggunakan mikroskop dengan pembesaran optik hingga 500X.

Uji Kekerasan

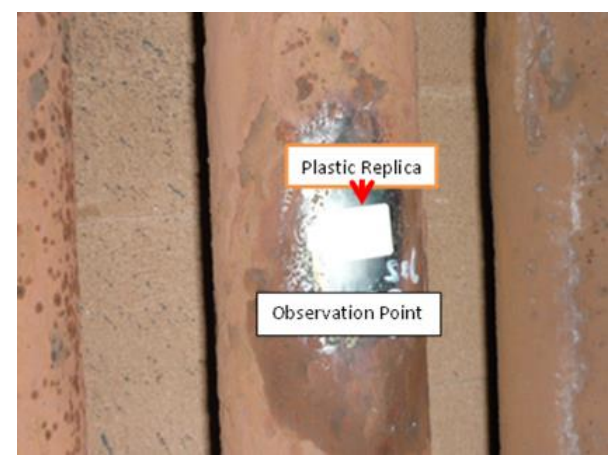

Gambar 1.

Hasil Preparasi dengan Teknik Replika
Pengujian ini dilakukan menggunakan mesin portable hardness tester. Adapun posisi uji kekerasan dilakukan pada area material dasar di sekitar permukaan tube heater yang telah dipreparasi dengan metode metalografi.

\section{HASIL DAN PEMBAHASAN}

\section{Hasil Penelitian}

Kajian terhadap material tube heater yang telah beroperasi pada temperatur cukup tinggi dalam kurun waktu lebih dari 15 tahun merupakan fokus dari penelitian ini. Adapun hasil penelitian terhadap material tersebut adalah sebagai berikut.

\section{Pengamatan Visual}

Hasil pengamatan visual yang terlihat pada gambar 2 menunjukkan bahwa umumnya kondisi permukaan luar tube heater telah dipenuhi oksida besi sebagai akibat dari proses operasi tube pada temperatur tinngi

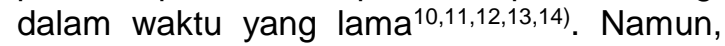
pada semua permukaan tube secara visual tidak terlihat adanya kerusakan yang cukup serius seperti bulging, retak, hot spot, leakage dan lainnya ${ }^{15,16)}$.

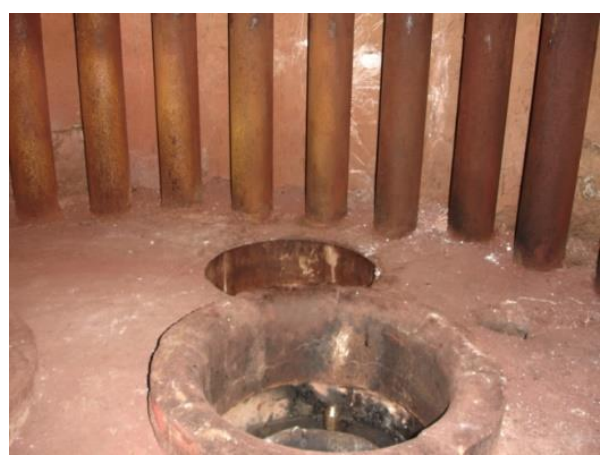

( a )

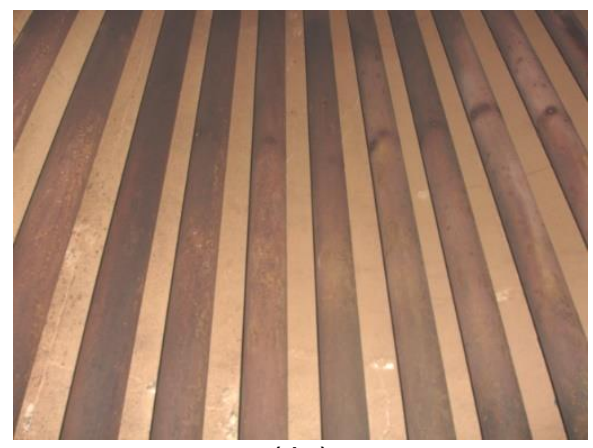

(b)

Gambar 2.

Visual tube heater menunjukkan kondisi tube secara umum masih dalam keadaan baik 
Pemeriksaan Struktur mikro

Pemeriksaan struktur mikro dilakukan secara acak (random) dengan sketsa lokasi pengambilan sampel pada gambar 3. Hasil pemeriksaan struktur mikro yang terlihat pada gambar 4 yang menunjukkan bahwa kondisi struktur mikro material tube heater yang semula berupa normal ferit dan perlit yang mulai mengalami perubahan/ transformasi menjadi ferit dan spheroidisasi perlit. Dari semua hasil observasi struktur mikro tidak memperlihatkan adanya kerusakan maupun cacat lainnya.

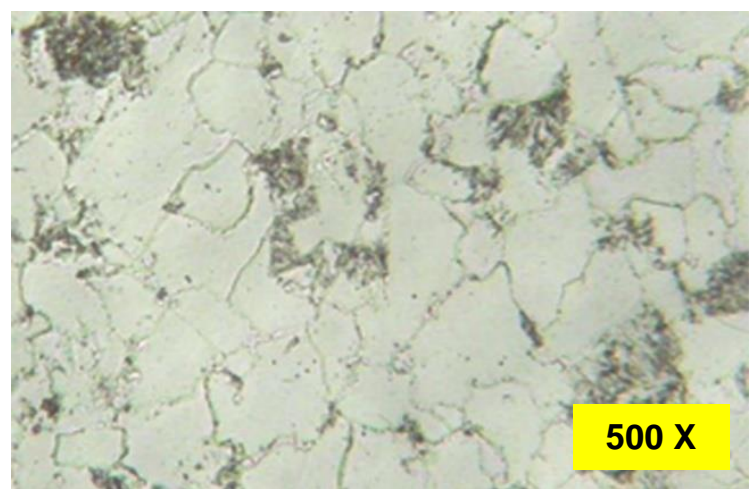

( a )

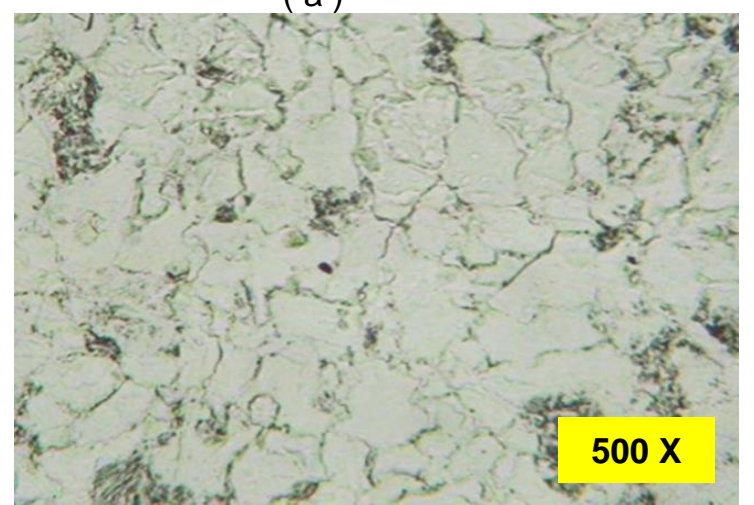

(c)

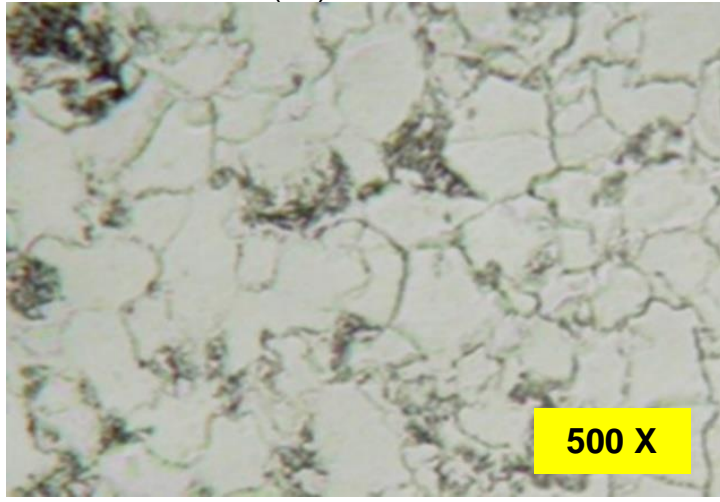

(e)

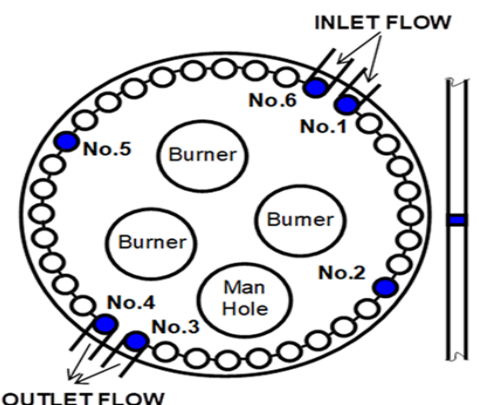

OUTLET FLOW

Keterangan:

$1,2,3 \ldots=$ Nomor lokasi pemeriksaan

= Lokasi tube yang dipemeriksaan

Gambar 3.

Sketsa susunan tube heater dan lokasi pemeriksaan mikro struktur dan uji kekerasan

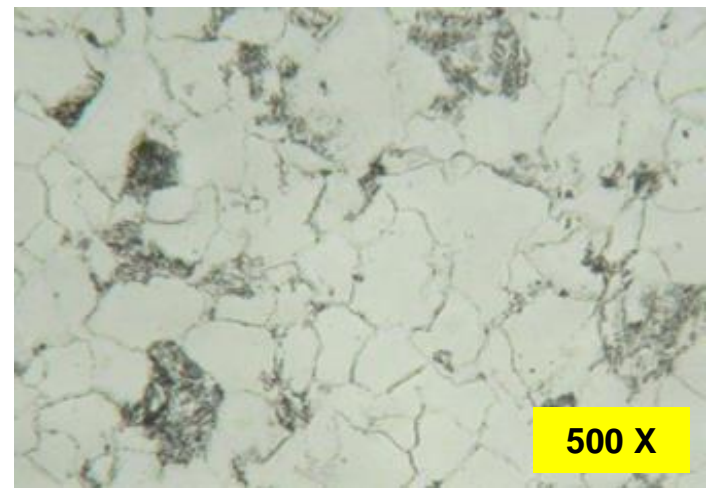

(b)

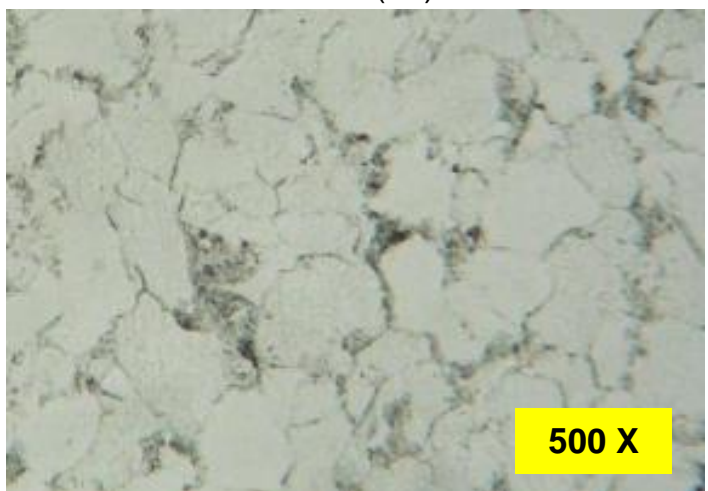

(d)

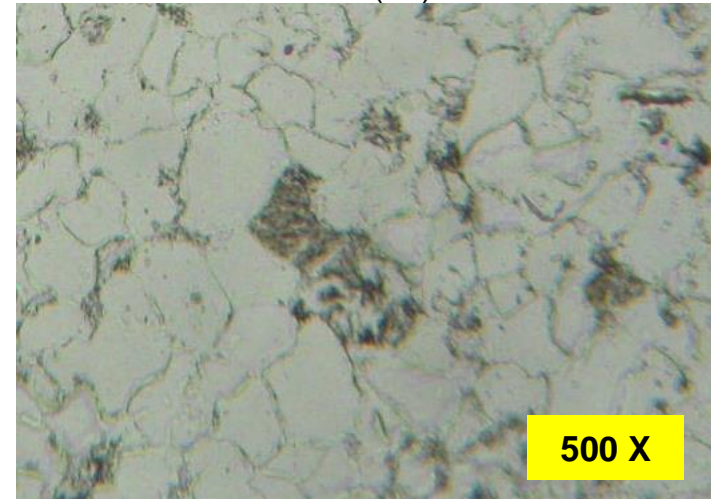

( f )

Gambar 4.

Struktur mikro material radiant tube. a) lokasi No.1, b) lokasi No. 2 ,

c) lokasi No. 3, d) lokasi No. 4, e) lokasi No. 5, f) lokasi No. 6 


\section{Uji Kekerasan Tube}

Hasil uji kekerasan yang dilakukan pada semua lokasi pemeriksaan struktur mikro seperti terlihat pada tabel 1, menunjukkan bahwa nilai kekerasan minimum terjadi pada lokasi tube nomor 4 yaitu sebesar $121 \mathrm{HB}$.

Tabel 2.

Hasil Uji Kekerasan

\begin{tabular}{ccc}
\hline $\begin{array}{c}\text { No. Lokasi } \\
\text { UJI }\end{array}$ & $\begin{array}{c}\text { Kekerasan } \\
(\mathrm{HB})\end{array}$ & $\begin{array}{c}\text { Minimum } \\
(\mathrm{HB})\end{array}$ \\
\hline 1 & $128,125,128$ & 125 \\
2 & $127,129,126$ & 126 \\
3 & $125,128,125$ & 125 \\
4 & $121,124,122$ & 121 \\
5 & $128,124,125$ & 124 \\
6 & $132,129,131$ & 131 \\
\hline
\end{tabular}

\section{Pembahasan}

Material radiant tube heater secara visual terlihat telah mengalami pertumbuhan lapisan oksida pada semua permukaannya akibat terekspos temperatur tinggi selama proses pengoperasian heater berlangsung. Walaupun demikian, pada semua permukaan tidak terlihat adanya indikasi kerusakan cukup signifikan yang dapat menimbulkan percepatan kerusakan tube heater tersebut seperti hot spot, retak, bulging dan kerusakan lainnya.

Struktur mikro material berupa fasa ferit $(\mathrm{Fe})$ dan perlit $\left(\mathrm{Fe}_{3} \mathrm{C}\right)$. Di dalam struktur mikro terlihat adanya pengendapaan butir karbida di batas butir dan struktur mikro material tube mulai mengalami proses transformasi dari normal ferit dan pearlit menjadi ferit dan perlit yang terspheroidisasi, dimana perlit yang semula berbentuk lamellar (memanjang) mulai berubah menjadi bentuk globular (bulat). Shepoidisasi terlihat merata dan batas butir dari struktur mikro masih cukup jelas dan belum terlihat adanya pertumbuhan butir, creep void maupun cacat lainnya ${ }^{17,18,19)}$.

Hal tersebut membuktikan bahwa material radiant tube heater secara metalurgi tidak mengalami degradasi/ kerusakan struktur mikro yang cukup signifikan, meskipun material tube heater tersebut telah dioperasikan dalam waktu cukup lama dan pada temperatur tinggi. Dengan kata lain kondisi struktur mikro atau butiranbutiran material masih sangat baik.

Dari uji kekerasan juga diketahui bahwa nilai kekerasan terendah terjadi pada lokasi pemeriksaan No. 4 yaitu sebesar rata-rata 121 HB (hardness brinnell). Karena nilai kekerasan dari material sangat berkaitan dengan nilai kekuatannya, maka dengan menggunakan persamaan konversi dari nilai kekerasan ke nilai kekuatan tarik (tensile strength) 20,21) akan diperoleh nilai minimum kekuatan tarik aktual material tube heater saat ini yaitu sebesar 417 $\mathrm{MPa}$. Sedangkan, nilai minimum kekuatan (tensile) dari spesifikasi standar acuan JIS

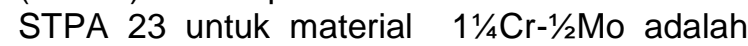
sebesar $412 \mathrm{MPa}$.

Dengan mengacu pada hasil-hasil observasi dan analisis tersebut dapat dikatakan bahwa material radiant tube heater di unit refinery masih layak dan handal untuk dioperasikan sesuai fungsi dan kondisi operasi normal atau kondisi operasi yang diterapkan selama ini.

\section{SIMPULAN}

Material radiant tube heater di unit refinery yang telah dioperasikan dalam proses pengolahan minyak bumi pada temperatur tinggi masih dalam kriteria baik secara metalurgi, di dalam struktur mikro material tidak ditemukan adanya kerusakan atau degradasi struktur mikro yang cukup signifikan, dimana batas butir masih sangat jelas, besar butir masih normal, fasa struktur masih ferit dan perlit. Dan sifat mekanis material dari hasil uji kekerasan yang dikonversikan ke dalam kekuatan tarik (ultimate strength) masih dalam kriteria standar

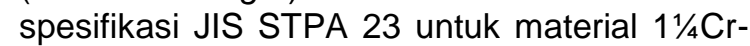
$1 / 2$ Mo.

Material radiant tube heater di unit refinery masih layak dan handal untuk difungsikan kembali sesuai dengan kriteria desain operasi atau sesuai prosedur operasional yang telah diterapkan selama 15 tahun sebelumnya.

\section{UCAPAN TERIMA KASIH}

Kepada tim manajemen reliability PERTAMINA RU II dumai dan manajemen B2TKS BPP Teknologi, atas kesempatan yang diberikan untuk studi ini.

\section{DAFTAR PUSTAKA}

1. H. Assan Al-Haj Ibrahim*, M. Mourhaf AlQassimi, Calculation of Radiant Section Temperatures in Fired Process Heaters, Chemical Engineering and Science, AlBaath University, Homs (2013) 55-61.

2. Yianis Selidinis, Introduction to Fired Heaters Pt 2: Components, Brochure; Scelerin Heater, February 13, 2019. sales@scelerin.com.

3. Z. Jegla, J. Kohoutek and P. Stehlik, Design and operating aspects influencing fouling 
inside radian coils of fired heater operated in crude oil distillation plants, Proc Int Conf Heat Exch Foul Clean, Greece, 2011.

4. A. Garg, These design, operation and revamp guidelines will help increase run lengths and efficiency. Improve vacum heater reliability, J. Hydrocarbon Processing, March (1999) 161-172.

5. API Standard 560, Fired Heaters for General Refinery Service, Third edition, May (2001).

6. Hills, Fired heater health monitoring and reliability management in challenging times, J. Inspectioneering, (22) (2) April 2016.

7. M. Syahril dan Amin Suhadi, Analisa Kondisi Aktual Pipa Radian Furnace Pada Unit Pengolahan Minyak Mentah, Jurnal Sains dan Teknologi Indonesia, Material, (16) (2) (2014), 10-19.

8. Japanese Standard Association, Ferrous Materials \& Metallurgy II, Japanese Industrial Standard Handbook, Japan, 2015.

9. Standard Practice for Production and Evaluation of Field Metallographic Replicas, ASTM E1351, January 2012.

10. Juntao Yuan et al., Investigation on the Enhanced Oxidation of Ferritic/Martensitic Steel P92 in Pure Steam, J. Materials, (2014) 7, 2772-2783.

11. LIOGTa, General Manual of Tube Heater, Detroit Radiant Products Co, USA, 2016.

12. David M. G and Antony T. Fry, The Early Morphological Development of the Near Surface Region of Pickled Grade 91 Tubing Exposed to Steam and Its Long Term Implications, J. Metals,(6) (62) (2016), 1-16.

13. K.B.Yoona and D.G.Jeong, Oxidation failure of radiant heater tubes, J.
Engineering Failure Analysis, (6) (1998) 101 $-112$.

14. Majid Asnavandi, et al., Fire-Side Corrosion: A Case Study of Failed Tubes of a Fossil Fuel Boiler, International Journal of Corrosion, 2017, 1-8.

15. Manoj Mittal, Tube Failures in Pulverised Coal Fired Boilers: An Investigation, Lambert Academic Publishing, 14 February 2017.

https://www.researchgate.net/publication/3 13680133

16. Tony Ennis, Safety in the design of thermal fluid heat transfer systems, SYMPOSIUM 155, Institution of Chemical Engineers, UK, 2009, 162-169.

17. D. Luoaet all, Spheroidisation of Hypereutectoid State of Nano-structured Bainitic Steel, J. Materials Science and Technology, University of Cambridge, (30) (2014) 1282-1286.

18. Michael P. Carroll, Metallographic Characterization of Thermal Damage in Boiler Tubes, J. Microanalysis, Microscopy Society of America, (21) (2015) $589-590$.

19. Daniel Leite Cypriano Neves et al, Stress and Integrity Analysis of Steam Super heater Tubes of a High-Pressure Boiler, J. Materials, Vol 7 (1) (2004) 155-161.

20. E.J. Pavlina and C.J. Van Tyne, Correlation of Yield Strength and Tensile Strength with Hardness for Steels, ASM Inter. J. Materials Eng. and Perform, 17 (6) 2008, 888-893.

21. M. Gaško, G. Rosenberg, Correlation between hardness and tensile properties in ultrahigh strength dual-phase steels, J. Mat. Eng, Slovak Academy of Sciences, 18 (2011) 155-159. 